\title{
GESTÃO DE PESSOAS POR COMPETÊNCIA NO SETOR PÚBLICO
}

\author{
MANAGEMENT OF PEOPLE BY COMPETENCE IN THE PUBLIC SECTOR
}

\author{
Tiago Corrêa Vargas ${ }^{1}$ \\ Felipe da Silva Linhares ${ }^{2}$ \\ Tiago Vargas Guedes ${ }^{3}$ \\ Luiz Eduardo Mazullo Cernicchiaro ${ }^{4}$ \\ Adriano Dias de Oliveira ${ }^{5}$ \\ Elaine Cantini ${ }^{6}$
}

RESUMO: A realização deste trabalho tem como propósito poder proporcionar um entendimento melhor a respeito da Gestão por Competência na esfera do setor público. Há muito tempo sabe-se que existem reclamações dos cidadãos referentes ao péssimo atendimento proporcionados pelos funcionários dessas instituições. Devido à relevância dessa situação, existe a possibilidade de que este problema esteja a ocorrer é pela ineficiência de um sistema de Gestão de Pessoas em que se procure atender, de forma planejada e sistemática, a satisfação das necessidades do cidadão. Devido a este motivo e alguns outros, este trabalho tem como seu objetivo analisar os modos de como atua a Administração Pública referente à maneira que ela realiza o gerenciamento de pessoas, a devida importância de ter na Gestão Pública um modelo de sistema que busque nos servidores públicos a competência não apenas técnico-teórico, mas que seja proporcionado treinamento para que as capacidades destes servidores possam ser desenvolvidas e que satisfaçam aos anseios da população.

Palavras-chave: Gestão. Competência. Setor Público.

1 Licenciatura em Educação Física - Universidade Luterana do Brasil - ULBRA - Cachoeira do Sul e pósgraduado em Administração Pública. Email: tiago-vargas@susepe.rs.gov.br.

${ }^{2}$ Licenciatura em Educação física pela Universidade Luterana do Brasil- ULBRA em Cachoeira do sul/ RS e pós-graduadoem Administração Pública. E-mail: felipe-linhares@susepe.rs.gov.br

3 Bacharel em Administração - Universidade da Região da Campanha URCAMP - Alegrete/ RS e pósgraduadoem Segurança Pública pela FAVENI.E-maill: tiago-guedes@susepe.rs.

4 Bacharel em Direito pela Universidade Luterana do Brasil ULBRA e pós- graduado em Direito Processual Civil pela UNISC.E-mail: luiz-cernicchiaro@susepe.rs.gov.br.

${ }^{5}$ Formado em História pela Unisinos e pós- graduado em Segurança Pública - FAVENI. E-mail: adrianodias@susepe.rs.gov.br.

${ }^{6}$ Bacharel em Fisioterapia- -Centro Universitário Metodista- IPA e especialista em Gestão de Sistemas Prisionais. E-elaine-cantini@susepe.rs.gov.br. 
ABSTRACT: The purpose of this work is to provide a better understanding of Management by Competence in the sphere of the public sector. It has long been known that there are complaints from citizens regarding the poor service provided by the employees of these institutions. Due to the relevance of this situation, there is a possibility that this problem is occurring is due to the inefficiency of a People Management system in which it seeks to meet, in a planned and systematic way, the satisfaction of the citizen's needs. Due to this reason and some others, this work aims to analyze the ways in which Public Administration acts regarding the way in which it manages people, the due importance of having in Public Management a system model that searches the servers public not only the technical-theoretical competence, but that training is provided so that the capacities of these servants can be developed and that satisfy the population's desires.

Keywords: Management. Competence. Public sector.

\section{INTRODUÇÃO}

A escolha do tema surgiu a partir da realidade das Administrações Públicas no que diz respeito à Gestão de Pessoas, traduz como devem ser prestados serviços de qualidade por servidores competentes e eficientes.

Os servidores são selecionados através de concurso público de provas e títulos e após a aprovação, são alocados em diversas áreas, sendo que a grande maioria não possui nenhum tipo de

experiência. São muito capazes intelectualmente, porém inúmera vez não tem o perfil adequado para desempenhar aquela função onde foi alocado. Devido a esses problemas que são frequentes, existe a necessidade da gestão de competência para que ela possa saber onde aquele servidor tem melhor perfil para desempenhar a sua função e tornar-se mais eficiente no serviço público.

É notável a necessidade em algumas instituições públicas que alguns servidores necessitam de uma qualificação, tendo em vista algumas deficiências no atendimento, esclarecimento de informações e despreparo para lidar com o público. Em alguns casos, isso acontece devido ao servidor ser concursado e estar estabilizado na função, isso gera um comodismo, o qual atrapalha no desempenho da função.

Diante deste cenário, verificou-se a necessidade de criar um método de poder realizar uma avaliação e uma qualificação constante do servidor, mesmo ele já estando estabilizado no serviço público.

Nesse sentido, buscou-se suporte de material bibliográfico para dar amparo no que se refere ao tema deste Artigo Científico, podendo assim visualizar a problemática da falta de motivação e de investimento dos órgãos públicos nos seus recursos humanos. 


\section{Tema e Objetivo de Estudo}

A Administração Pública é responsável por realizar serviços postos à disposição da população, quando os bens e serviços prestados são de interesses da coletividade, a administração é pública, devendo visar o bem comum em benefício da sociedade.

A administração é o instrumento que o Estado dispõe para realizar as suas políticas de governo e a modernização da administração pública é o processo contínuo em que modelos são constantemente implantados na expectativa de que a estrutura governamental possa atender de forma eficiente e eficaz as demandas sociais.

Atualmente a grande maioria dos serviços públicos prestados é de péssima qualidade, percebe-se o descaso com as suas demandas e das esperas em longas filas. Cabem aos nossos governantes encontrarem novas tecnologias, metodologias e novos modelos de Gestão de Pessoas para suprir, com maior rapidez e eficácia, a escassez de servidores e a falta de qualificação profissional para atender à demanda intensa da população.

Poder proporcionar um aumento na qualidade e eficiência nos serviços do setor público são os novos desafios da administração.

A valorização das competências é uma forma inovadora nas organizações públicas, a existência de indicadores é fundamental para a gestão baseada nos desempenhos dos servidores. É necessário criar um ambiente de trabalho que estimule a criatividade, autonomia e motivação durante os seus turnos de serviços.

O principal objetivo da efetivação da Gestão por Competências é o alinhamento dos conhecimentos, das habilidades e das atitudes dos servidores públicos aos valores e à missão da instituição, reduzindo a distância entre os serviços efetivos prestados pelos integrantes da organização e o desempenho que a instituição necessita.

A área de gestão de pessoas é de extrema importância nas organizações públicas, pois elas direcionam os servidores para os trabalhos que tenham maiores qualificações, podendo proporcionar mais condições e oportunidade para o crescimento profissional e pessoal. Sendo assim as organizações conseguem alcançar os seus objetivos traçados.

A Constituição Federal (CF/88) em seu artigo 37 aborda a Administração Pública: 
Art. 37. A administração pública direta e indireta de qualquer dos Poderes da União, dos Estados, do Distrito Federal e dos Municípios obedecerá aos princípios de legalidade, impessoalidade, moralidade, publicidade e eficiência e, também, ao seguinte: (...)

Os referidos princípios administrativos devem ser os norteadores dos administradores e servidores públicos, pois visam uma gestão mais transparente e profissional com ações que visam o atendimento das demandas, anseios e necessidades da população. Portando a administração deve cumprir a função para a qual foi criada.

Cabe ao setor de Recursos Humanos/Gestão de Pessoas localizarem e identificarem as necessidades ou carências que estão a acontecer em cada setor, um problema específico ou em toda à organização.

No novo modelo de Gestão de Pessoas, o foco está na competência do servidor para desempenhar a sua função, deverá ser estimulado o conhecimento, habilidades, julgamento e atitude. Através do estímulo dessas competências teremos servidores mais preparados para realizar as suas funções e alcançar as metas propostas pela instituição. Devemos proporcionar aos servidores um treinamento constante, condições de trabalho e uma remuneração adequada. Assim poderemos atrair e manter os servidores nas nossas instituições.

Por mais que existam obstáculos e desafios, a implantação efetiva da Gestão por Competência pode transformar gradualmente, a realidade do nosso serviço público, haja vista que ele pode se tornar mais eficiente seja na qualidade dos serviços prestados, bem como na qualificação dos agentes públicos, de acordo comas habilidades e comportamentos.

A Administração Pública pode ser de duas formas: a forma direta e a indiretamente. Independentemente da forma em que será a administração, ela deve primar pelos princípios constitucionais.

\section{Administração Pública Direta}

A Administração Pública direta é formada pelo conjunto de órgãos públicos ligados diretamente a esfera governamental (União, Estados, Municípios e Distrito Federal), não possue personalidade jurídica própria, onde as despesas são realizadas diretamente por meio do orçamento de cada esfera. 
O Decreto-Lei 200/1967, estabelece no seu artigo $4 . .^{\circ}$ - A administração federal compreende: I - a administração direta, que se constitui dos serviços integrados na estrutura administrativa da Presidência da República e dos ministérios.

A Administração Direta atua em políticas públicas de caráter essencialmente de Estado, como: Defesa Nacional, Relações Exteriores, Saúde, Previdência, Educação e diversas outras áreas.

Os servidores públicos lotados na Administração Direta são selecionados através de concurso público e possuem vínculo estatutário junto ao Estado.

A autonomia dos entes federados é possível devido à divisão das competências, isto é, cada ente é independente na sua esfera de atuação e competência, não sofrendo interferência um do outro.

\section{Administração Pública Indireta}

A Administração Pública Indireta, é composta por entidades que, por meio de descentralização de competências do governo, foi criada para desempenhar papéis nos mais variados setores da sociedade e prestar serviços. Ela executa algumas tarefas de interesse do Estado por outras pessoas jurídicas, quando não se realizará através dos seus próprios órgãos, então, transfere a sua titularidade ou execução a outras entidades.

Podemos citar como exemplo às Autarquias, foi criado através de lei e prestam serviços à população descentralizadamente, nas mais diferentes áreas. Um exemplo de Autarquia é o INSS (Instituto Nacional de Seguridade Social), que está vinculada ao Ministério do Desenvolvimento Social e Agrário.

Também fazem para da Administração Pública Indireta as Fundações, elas são entidades sem fins lucrativos, constituídas para um fim específico de interesse público (educação, saúde, cultura e pesquisa), como exemplo temos o Instituto Brasileiro de Geografia e Estatística (IBGE), tem como atribuições as geociências e estatísticas sociais, o que inclui realizar censos e organizar as informações obtidas.

O Decreto-Lei 200/1967, estabelece em seu artigo $4^{\circ}$ - A administração federal compreende:

II - a administração indireta, que compreende as seguintes categorias de entidades, dotadas de personalidade jurídica própria:
a) autarquias;
b) empresas públicas;
c) sociedades de economia mista; 
d) fundações públicas.

Tanto na Administração Pública Direta e Indireta a transparência das ações é fundamental, visto que ambas estão sob o alcance de sanções da lei.

\section{Gestão de Pessoas na Área Pública}

O planejamento é de extrema importância para o sucesso da organização, principalmente quando se estiver a tratar em esfera pública. Então a área dos recursos humanos deve fazer parte deste planejamento. Ao longo dos anos percebeu-se que as administrações públicas, não deram o devido valor à importância desta área.

Houve um tempo em que as funções públicas eram um cabide de empregos, onde havia o "apadrinhamento" de servidores, falta de profissionalismo e de capacitação para o exercício da função. Porém, com a Constituição de 1988 iniciou-se um processo de mudanças, onde se realizou uma Administração Pública com maior profissionalismo, transparências e maior igualdade de oportunidades através do ingresso no serviço público através de concursos.

Importantes mudanças ocorreram no setor público com a implementação da Constituição Federal de 1988, essas mudanças tinham como objetivo tornar o setor público mais transparente e profissional. Foi introduzida na administração pública a realização de concursos e a estabilidade no emprego.

Através da C.F 88 alguns objetivos foram atingidos, porém, por outro lado criou-se outra situação muito inconveniente refere-se ao excesso de servidores em algumas repartições e também não poder trocar os servidores quando se precisa, devido ao concurso prestado e a estabilidade.

Para tentar solucionar esse problema, é necessário que à administração de recursos humanos desenvolva um sistema de incentivos para o servidor, pois é evidente a falta de uma política de formação, capacitação permanente e de remuneração coerente com o exercício da função.

Conforme a ENAP (2007, p.32) os profissionais de recursos humanos são responsáveis em oferecer o suporte necessário para a Gestão de Pessoas, estabelecendo critérios a respeito de questões como: "planejamento da força de trabalho, implementação de ações de desenvolvimento profissional, criação de carreiras e estruturas remuneratórias, avaliação de desempenho, gestão por competência, entre outros.". 
As organizações públicas são permanentes, mas são submetidas a mudanças constantemente com a mudança de governo, a grande dificuldade está em manter organizados os serviços com essas constantes mudanças. É importante que haja uma padronização do serviço, pois assim, independentemente da troca de governo, o serviço será prestado com a mesma eficiência. Uma grande dificuldade enfrentada é de realizar um concurso adequado para cada área, e após a seleção deste candidato é de mantê-lo trabalhando no serviço público.

Dessa forma, a Gestão por Competências revela-se em um modelo de gestão planejada e estratégica que permite a identificação das competências organizacionais necessárias para que a instituição atinja os seus objetivos. Ao identificar tais competências, a instituição torna-se capaz de mapear as competências humanas, fomentando o planejamento estratégico. É o momento de identificação de lacunas a serem preenchidas com o desenvolvimento do novo modelo de gestão.

Durante a aprendizagem em grupo busca-se desenvolver as competências e um modo de compartilhá-las, essa é a principal meta das instituições públicas. É muito importante que o servidor compreenda que a instituição que ele trabalha busca uma gestão por competência, através disso ele vai se sentir com mais oportunidades de crescimento profissional e em um ambiente mais prazeroso de trabalho. A busca constante pelo conhecimento, novas habilidade e experiências devem ser comandadas pela Gestão por Competência que tem uma função fundamental nessa nova fase da busca pela qualidade no serviço público, onde constantemente ocorrem mudanças pelas tecnologias e entre outras, o servidor precisa estar sempre em um processo de evolução constante onde o objetivo principal é de prestar um serviço de qualidade aos nossos cidadãos.

\section{Carreira, Cargos e Remuneração}

A estabilidade é um fator que tona o serviço público muito atraente. Porém, ela pode fazer com que um servidor caia em uma armadilha de apenas trabalhar preocupado com a demanda.

A falta de um plano de carreia faz com que o servidor público fique a esperar o tempo passar durante a sua vida funcional. Não existe uma política de remuneração adequada, qualificação, treinamentos e entre outros.

Essa falta de interesse no servidor é o reflexo da inexistência de uma política que valorize a competência, iniciativas e as demais qualidades que se espera de um servidor público engajado em realizar a sua função. 
Há muito tempo a Política está envolvida no serviço público, principalmente quando ocorrem as nomeações, promoções, realocações e mais algum tipo de benefício na carreira. Sendo que na maioria das vezes esses servidores indicados não têm competência alguma para exercerem a função na qual foram beneficiados.

Neste novo modelo de Gestão por Competências é necessário que haja uma diminuição dos cargos ocupados por servidores que foram indicados, sendo que é necessário valorizar o servidor que durante a sua vida funcional buscou sempre pela qualificação, realizando treinamentos e desenvolvendo as suas competências. Além de tornar mais justa à forma de promoção a qualidade dos serviços prestados vai ser superior e de melhor qualidade.

Uma boa iniciativa para mudar essa realidade e manter os servidores motivados seria através de um Plano de Carreira, nele devem estar os itens considerados para um servidor progredir profissionalmente, também deve estar presente os fatores que estão relacionados com um desempenho abaixo das expectativas, como avaliações dos gestores que indicam um rendimento insatisfatório.

Por isso, é interessante que sejam adotadas medidas que valorizem o esforço do funcionário público em evoluir e os resultados proporcionados por ele para a organização.

\section{Desenvolvimento de Competência e Treinamento}

O ser humano está em constante evolução, e para que isso ocorra deve ele desenvolva as suas habilidades e adquira conhecimentos frequentemente. Essas qualidades são muito úteis para as instituições públicas, pois através disso ele também vai buscar ser um servidor mais qualificado para poder resolver as demandas do seu trabalho.

Aproveitando essa qualidade, as instituições devem disponibilizar treinamentos para o desenvolvimento das competências e habilidades. Isso irá gerar maior conhecimento e aprendizado aos servidores, e deve-se estimular na equipe para que haja o compartilhamento dos conhecimentos.

Conforme Brandão e Guimarães (200I), atividades que visam desenvolver as competências necessárias das pessoas, auxiliam na administração pública no gerenciamento da carreira e no processo de empregabilidade. Interessante que desde o primeiro instante do servidor dentro da organização, ele tenha a visão de um plano de carreira que seja acessível e viável, que contemplo as suas necessidades de crescimento pessoal e profissional, que traga a tona as suas competências para 
progressão funcional, o estimulando a permanecer na empresa em razão de sentir-se valorizado e com possibilidades de ascensão a níveis mais interessantes de crescimento profissional.

Investir em treinamentos e abordagens que o torne cada vez mais adaptado e diferenciado no seu setor é essencial para que tenha uma carreira pública gratificante e para que aproveite oportunidades que venham a aparecer durante a sua carreira. A busca pelo aperfeiçoamento pessoal e profissional, nunca deve deixar de existir, ele deve fazer cursos e treinamentos em áreas estratégicas que gostaria de desenvolver, adquirindo assim novas competências e habilidades.

Saber colaborar e contribuir com outros profissionais em prol de objetivos comuns, compartilhando recursos e experiências, é fundamental para o sucesso da instituição pública, o desenvolvimento dessa competência é essencial.

\section{Considerações finais}

Enfim, ao realizar este trabalho foi possível verificar alguns dos motivos que levam a discutir a qualidade da prestação do serviço público, vimos que vários podem ser os fatores causadores dessa ineficiência destes serviços prestados no nosso país.

Verificaram-se muitas das causas desse problema, entre elas, podemos citar o comodismo de certos servidores que devido à estabilidade acaba demonstrando despreocupação com as suas funções, a desmotivação, a falta de um ambiente com estrutura e equipamentos adequados e entre outros.

Porém, também encontramos algumas das soluções para tentar resolver esta situação. Não adianta apenas desenvolver estudos teóricos, mas que através da aplicação deles ocorra uma mudança nos serviços prestados. É de extrema importância à criação de políticas voltadas à implantação da Gestão de Pessoas no setor público, através dela será possível prestar um atendimento melhor ao cidadão e manter os servidores motivados, qualificados e valorizados.

É necessário que a Administração Pública esteja focada na busca da excelência nos seus serviços, focando em uma administração comprometida com a população, além de estratégias que valorizem o servidor não esquecendo que o aprimoramento e a valorização devem ser constantes.

É necessário que se tenha o entendimento que a Gestão de Pessoas atue como facilitadora para integrar todas as áreas da administração visando auxiliar no desenvolvimento das competências dos servidores. 
Afinal, tanto a Administração Pública Direta ou Indireta tem como dever constitucional de prestar um serviço de qualidade a população, o qual atenda aos seus anseios.

\section{Referências}

BRANDÃO, H. P.; GUIMARÃES, T. A. Gestão de competências e gestão de desempenho: tecnologias distintas ou instrumentos de um mesmo constructo. Revista de Administração de Empresas, vol. 4I, n.I, p. 8-I5, jan./mar. 200I.

BRASIL. Constituição: República Federativa do Brasil de 1988. Brasília, DF: Senado Federal, 1988.

BRASIL. República Federativa do Brasil. Decreto-Lei № 200 Art. 4o de 1967. Brasília, DF.

CHIAVENATO, Idalberto. Treinamento e Desenvolvimento de Recursos Humanos. Ed.Manole Ltda. 7 Edição, 2010.

ENAP- Diretoria de Desenvolvimento Gerencial/Coordenação Geral de Educação a Distância Gestão estratégica de pessoas e plano de carreira - atualizado em: out. 2007. Módulo or - item 03.

GIL, Antônio Carlos. Como elaborar projetos de pesquisa. São Paulo: Editora Atlas S.A, 2009.

MEIRELLES, Hely Lopes. Direito Administrativo Brasileiro. 34. Ed. São Paulo: Malheiros, 2008.

PASSOS, Elizete. Ética nas Organizações. Ed. Atlas S.A., 2012.

ULBRA. Desenvolvimento de Pessoas. Ed. Ibpex, 2010. 